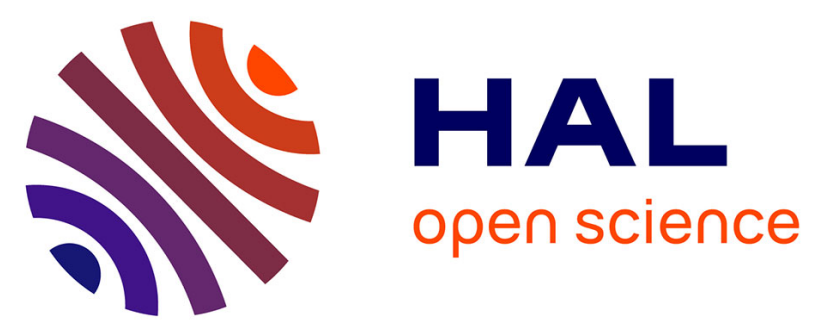

\title{
Probabilistic assessment of the cumulative dietary acute exposure of the population of Denmark to organophosphorus and carbamate pesticides
}

\author{
Bodil Hamborg Jensen, Annette Petersen, Tue Christensen
}

\section{- To cite this version:}

Bodil Hamborg Jensen, Annette Petersen, Tue Christensen. Probabilistic assessment of the cumulative dietary acute exposure of the population of Denmark to organophosphorus and carbamate pesticides. Food Additives and Contaminants, 2009, 26 (07), pp.1038-1048. 10.1080/02652030902859754 . hal00573880

\author{
HAL Id: hal-00573880 \\ https://hal.science/hal-00573880
}

Submitted on 5 Mar 2011

HAL is a multi-disciplinary open access archive for the deposit and dissemination of scientific research documents, whether they are published or not. The documents may come from teaching and research institutions in France or abroad, or from public or private research centers.
L'archive ouverte pluridisciplinaire HAL, est destinée au dépôt et à la diffusion de documents scientifiques de niveau recherche, publiés ou non, émanant des établissements d'enseignement et de recherche français ou étrangers, des laboratoires publics ou privés. 


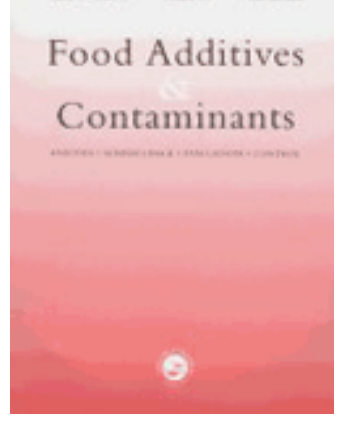

\section{Probabilistic assessment of the cumulative dietary acute exposure of the population of Denmark to organophosphorus and carbamate pesticides}

\begin{tabular}{|r|l|}
\hline Journal: & Food Additives and Contaminants \\
\hline Manuscript ID: & TFAC-2008-358.R1 \\
\hline Manuscript Type: & Original Research Paper \\
\hline Author: & 23-Feb-2009 \\
\hline Complete List of Authors: & $\begin{array}{l}\text { Jensen, Bodil; Technical University of Denmark, National Food } \\
\text { Institute } \\
\text { Petersen, Annette; Technical University of Denmark, National Food } \\
\text { Institute } \\
\text { Christensen, Tue; Technical University of Denmark, National Food } \\
\text { Institute }\end{array}$ \\
\hline Mdditives/Contaminants: & Pesticides - organophosphorous \\
\hline Food Types: & Cereals, Fruit, Vegetables \\
\hline
\end{tabular}

\section{SCHOLARONE Manuscripts}


Keywords: Organophosphorus, Carbamates, Probabilistic, Cumulative, Acute exposure assessment, Relative Potency Factor, Food

\section{Introduction}

The acute and chronic exposure assessment of pesticides has usually been performed on a single pesticide basis. However, consumers can be exposed to more than one pesticide during a day as they eat various kinds of fruits, vegetables and cereals. Furthermore, the exposure to pesticides can arise from pesticides that have a common toxic effect because they have a common mode of action.

The organophosphorus and carbamate pesticides are examples of pesticides, which have the same mode of action since they are both acetyl cholinesterase inhibiting (AChE) compounds. They act on the central nervous system by inhibiting the enzyme responsible for the metabolism of acetylcholine, which transmits signals between nerve cells and between nerve and muscle cells. So it is of interest to estimate the cumulative exposure to these pesticides. More generally, Regulation (EC) No 396/2005 on maximum residue levels (MRLs) emphasizes the importance of developing a methodology that takes into account the cumulative and synergistic effects of pesticides (EU Commission. Regulation No 396/2005).

A cumulative acute exposure assessment for the population of Denmark to organophoshorus and carbamate pesticides has been performed previously using the deterministic estimate approach (Jensen et al. 2003). However, this approach did not take into account the fact that acute exposure to a pesticide can arise from more than one crop at the same time. Moreover, the deterministic approach is not suitable for estimating the exposure for the total population, which is also described in the "Opinion 
on acute dietary assessment" from the European Safety Authority (EFSA 2007). As described in the "Opinion on a request from EFSA to evaluate the suitability of existing methodologies" (EFSA 2008) and by Boon et al (2004), probabilistic modelling addressing the total population is needed in cases where you need to address several crops simultaneously, which is very likely when addressing a group of compounds and trying to assess the actual exposure. In the present study, we used the probabilistic approach to estimate the actual cumulative acute exposure to organophosphorus and carbamate pesticides in the population of Denmark. We are aware that this might be an overestimation because organophosphorus and carbamate pesticides do not have quite the same mechanism of action, as described by Van Raaij et al. (2005). One of the differences is that organophosphates inhibit the acethylcholine esterase nearly irreversibly, while the enzyme inhibition by carbamates is reversible. In a study performed by Boon et al. (2008) they therefore made a separate cumulative risk assessment for each of the two groups of compounds.

We used the Relative Potency Factor (RPF) approach as described by Wilkinson et al. (2000) to estimate the acute cumulative dietary exposure. In this approach, RPFs which express the relative toxic potency of each compound compared to an index compound (IC) are used to normalize the residue levels for all compounds in the group. We used the two index compounds, chlorpyrifos and methamidophos, in this study. Information on RPFs for the two compounds was obtained from the literature. Danish food consumption and residue data were used in the calculations.

\section{Methods}

\section{Food consumption data}

Intake estimates were based on consumption data obtained from the nationwide dietary survey performed in 2000-2002 by the Department of Nutrition, Technical University of Denmark (Andersen et al. 2005). The survey included 4068 people aged 4-75 years (the general population). Among these, the child population aged 4-6 years accounted for 231 people. The survey used a seven-day prospective food record with a pre-coded (semi-closed) questionnaire that included answering categories for the most commonly eaten foods and dishes in the Danish diet. The survey was distributed equally over the seven days of the week over the whole year to take into account possible seasonal variation in dietary habits. The questionnaire was organised according to a normal daily meal pattern. The body weight of each person was noted and used in the calculations.

\section{Pesticide residue data}

Residue data were obtained from the Danish pesticide monitoring programme during the period 2004-2007 including 6704 samples of fruits, vegetables and cereals. The samples were taken randomly throughout the year between commodities while the samples were not taken randomly between all commodities. Commodities with a high intake are taken every year. The samples were analysed for the content of about 190 different pesticides and metabolites and isomers of these compounds, including 48 organophoshorus pesticides and 9 carbamate pesticides. In total 22 organophosphates and three carbamates were found. For the assessment of the cumulative intake, RPFs could be found for 25 compounds when addressing chlorpyrifos while RPFs for only 18 compounds could be found when methamidophos was used as IC. Only commodities with at least one detectable residue above the limit of reporting (LOR) were included in 
the calculations. The selected/relevant pesticides were found in 43 commodities. No distinction was made between imported commodities and those of Danish origin.

\section{Relative Potency Factor (RPF)}

Since it was not the aim of this study to derive Relative Potency Factors for chlorpyrifos and methamidophos, these values were obtained from the literature. An index compound should be a compound with an extensive toxicological database and one of the best studied within the group (Wilkinson et al. 2000, EPA, 2001, Boon and Klaveren, 2003). RPFs for 25 organophosphorus and carbamate pesticides were included in this study and they were obtained from a Dutch and a Brazilian study (Boon and van Klaveren 2003, Caldas, 2006). The RPFs were derived from either using benchmark dose at $10 \%$ acetylcholinesterase inhibition $\left(\mathrm{BMD}_{10}\right)$ in rat brain or the nonobserved adverse effect level (NOAEL) with inhibition of acetylcholinesterase in brain or red blood cells. The RPFs used here are shown in table 1.

The residue concentration for a given pesticide is multiplied by the RPF value for this substance to give an equivalent content of the index compound. The cumulative acute exposure of organophosphorus and carbamate pesticides adjusted to an index compound can then be summed and compared to the ARfD for the index compound in the risk assessment.

\section{[Insert table 1]}

\section{Processing factors}

The use of processing factors is an important issue when assessing exposure to pesticides. In this study we used processing factors for commodities which were peeled. For citrus fruits, melon, banana and pineapples a processing factor of 0.1 was applied as provided from the report of the Danish monitoring programme (Poulsen et al. 2004). For rye, wheat grain and flour, the analytical results were also converted to estimates of residues in bread by multiplying the analytical results for wheat by 0.77 and by 0.65 for rye as provided by (Poulsen et al. 2004).

In the previous study performed by Jensen et al.(2003), processing factors were also applied for rinsing and washing/cooking. However in the EU, there is no common agreement on using processing factors for rinsing and washing and they have therefore not been included in this study.

Fore reasons of comparison, we also performed the cumulative intake calculations without processing.

\section{Levels below the limit of reporting (LOR)}

Levels below the LOR can be handled in various ways. Samples could contain residues below the LOR but higher than zero. So the question is which value is the most correct to use in the calculation, e.g. LOR, $1 / 2$ LOR or zero. For comparison, both $1 / 2$ LOR and zero were used in the cumulative exposure calculations for chlorpyrifos.

\section{Probabilistic acute intake calculations and uncertainty analysis}

The cumulative acute exposure was calculated using the Monte Carlo Risk Assessment program (MCRA 6.1), an internet-based program developed by Biometris and RIKILT - Institute of Food Safety, Wageningen UR, the Netherlands (Boer et al., 2007). The calculations were performed as follows. A person was randomly selected out of the 
consumption database. The consumption of each commodity that person ate in one day was multiplied by randomly selected normalised residue concentrations in the residue database. The intake was summed over foods giving an empirical estimate of the acute cumulative intake distribution. This calculation was performed 100,000 times for both the children and the general population giving a probability distribution for the pesticide intake. Processing factors as described above were applied in the calculations. No variability factors were used in the calculations. All estimates of possible intakes were adjusted for the individual body weights of each consumer. The exposures were specified at percentiles P50, P90, P95, P99, P99.9 and P99.99 and compared to the acute reference dose (ARfD) for chlorpyrifos and metamidophos, respectively. The percentile 99.9 was used as reference point. The uncertainty in the exposure calculations at each percentile expressed as a 95\% confidence interval was estimated using the Bootstrap technique (Manly, B.F.J.1998, Vose, D. 2000, Caldas 2006).

\section{Results}

\section{Food consumption and residue data}

Table II shows a summary of the food consumption data from the nationwide survey. White bread, followed by wine (only general population), rye bread and apple, had the highest mean consumption levels for all consumers (total population, both consumers and non-consumers) of the foods that contained at least one positive level of the pesticides addressed. Wine (only general population), followed by melon, apple, pear, white bread and rye bread, had the highest mean consumption on consumption days only (included only days with consumption) for both children and the general population. The highest percentage of consumption days was seen for white bread, rye bread, onion and apple for both children and the general population.

[Insert table II]

Figure 1 shows the ten most frequently found organophoshorus and carbamate pesticides in the Danish monitoring programme. Only commodities with at least one detectable residue were included in the assessment. Chlorpyrifos with more than 500 detects was clearly the most frequently found organophosphate pesticide in the monitoring program.

[Insert figure 1]

Table III shows the frequencies, mean concentrations in samples with positive content, and the main pesticides found in the 43 different commodities of fruit, vegetables and cereals. Exotic fruits, including passion fruit, mango, guava, carambola, kaki, rambutan and kumquat, had the highest detection frequency (13.9\%), followed by cherry $(12.5 \%)$, mandarin $(9.9 \%)$, lemon $(8.6 \%)$, asparagus $(7.7 \%)$, peach/nectarines $(7.6 \%)$, rice (7.3\%), grapefruit $(6.9 \%)$ and pineapple $(6.9 \%)$. Commodities with the highest mean concentrations were basil followed by lemon, grapefruit, dates, oranges and mandarin.

[Insert table III] 
Exposure and risk assessment using chlorpyrifos and methamidophos as index compounds

Table IV shows the cumulative acute exposure estimates using both chlorpyrifos and methamidophos as index compounds. Processing factors were applied and levels below the LOR were set to zero. The exposure calculated in $\mu \mathrm{g} / \mathrm{kg}$ bw/day was compared to the ARfD of 100 and $3 \mu \mathrm{g} / \mathrm{kg}$ bw/day for chlorpyrifos and methamidophos, respectively, (EU Com., doc. 3010, 2008). The exposure calculation is shown for both children and general population for both index compounds.

[Insert table IV]

When we used chlorpyrifos as index compound, the cumulative exposure was calculated to $1.8 \%$ and $0.8 \%$ of the ARfD of $100 \mu \mathrm{g} / \mathrm{kg}$ bw/day at the percentile 99.9 for children and the general population, respectively, while when we used methamidophos, the cumulative exposure was calculated to $31.3 \%$ and $13.8 \%$ of the ARfD of $3 \mu \mathrm{g} / \mathrm{kg}$ bw/day for children and the general population, respectively.

\section{Commodities and pesticides that contributed most to the intake}

Figure 2 shows the commodities that contribute most to the cumulative intake in relation to the index compound used in the calculation. It can be seen that the six commodities, apple, carrot, table grapes, pear, white bread and lettuce, contribute most to the intake whether chlorpyrifos or methamidophos was used as index compound. When we used methamidophos as index compound, wine contributed with $27.1 \%$ to the total intake, while when we used chlorpyrifos, wine was not among the commodities that contributed most. In both cases, apples contributed by far the most to the total intake.

[Insert figure 2]

\section{Effect of processing}

Figure 3 shows the nine commodities that contributed most to the cumulative acute intake using chlorpyrifos as index compound. The exposure is shown for the general population, and with and without processing factors being applied in the calculations.

\section{[Insert figure 3]}

It can be seen from the figure that apples contributed most to the intake in both cases. Due to a high detection frequency in citrus fruits, the commodities mandarin, oranges and grapefruit were among the 9 commodities that contributed most to the intake when no processing factors were applied. Banana and melon which are also peeled contributed also most to the intake when no processing factors were applied. When a processing factor of 0.1 was applied to the commodities which are peeled their contribution decreased in a very great extent and instead apples, carrot, table grapes, pear, white and rye bread, lettuce and peach/nectarine contributed most to the intake. When we used processing factors in the cumulative intake calculation, the exposure was 
calculated to $0.82 \%$ of the ARfD of $100 \mu \mathrm{g} / \mathrm{kg}$ bw/day at the 99.9 percentile for the general population.

\section{Effect of using $1 / 2$ LOR}

Figure 4 shows the estimated cumulative acute intake with processing factors applied compared to processing factors applied and $1 / 2$ LOR used in the calculations. The exposure calculation was performed with chlorpyrifos as index compound. The calculated intake was compared to the ARfD of $100 \mu \mathrm{g} / \mathrm{kg}$ bw/day for chlopyrifos and is shown for the general population. When $1 / 2$ LOR is used in the calculation, the cumulative exposure amounts to $1.0 \%$ of the ARfD at the 99.9 percentile.

[Insert figure 4]

\section{Discussion}

\section{Probabilistic approach}

When the deterministic approach is used, the acute exposure is addressed from one compound and one crop at a time. The exposure is calculated for the consumers only. But if we want to estimate the cumulative exposure, non-consumers should also be included in the calculations, because a consumer of one commodity can be a nonconsumer of other commodities. In the EFSA Opinion from 2007 (EFSA, 2007), it was also stated that the deterministic approach is not suitable for estimating the exposure for total populations (consumers and non- consumers).To address the exposure to multiple compounds simultaneously present in more than one food, we used the probabilistic approach. Other advantages in using the probabilistic approach include that the variation in the population's eating habits is taken into account and compared with individual bodyweights. The whole distribution of residues is used in the calculations and the uncertainties at different percentiles can be quantified.

\section{Percentile used as threshold of concern}

The percentile that should be used as the threshold of concern in the probabilistic exposure calculation depends on what risk the risk manager is willing to accept. The US EPA (EPA 2000) used the percentile 99.9 as reference point. This percentile was also used in this study to evaluate the risk for the consumer. As seen in Table III, the confidence interval is broader at the higher percentile of 99.99 due to higher sensitivity to uncertainties in data collection. This confirms that the calculated intake at this percentile should be treated with caution.

\section{Exposure and risk assessment using chlorpyrifos and methamidophos as index compounds}

The output from using the two different index compounds chlorpyrifos and methamidophos in the calculations is significantly different. When we used chlorpyrifos, the cumulative exposure was estimated to $0.8 \%$ and $1.8 \%$ of the ARfD of chlorpyrifos for the general population and the child population respectively; when we used methamidophos, the intake was calculated to $14 \%$ and $31 \%$ of the ARfD for the general and the child population respectively. At the percentile 99.99, the ARfD is 
exceeded by $14 \%$ with a $95 \%$ confidence interval of $74-196 \%$ of the ARfD using methamidophos as index compound. This indicates that a few consumers might exceed the ARfD, but as noted earlier the uncertainty at the percentile 99.99 is very high. So values at this percentile should be treated with caution.

When we addressed the cumulative intake for methamidophos, RPFs could only be found for 18 compounds compared with 25 compounds for chlorpyrifos. The cumulative intake would therefore have been even higher if RFPs could have been found for all the compounds found in the monitoring programme. The estimated intake using methamidophos as index compound can therefore only be used as an indication of what the cumulative intake is.

The RPFs derived for chlorpyrifos were all derived from NOAEL, while the majority of the RPFs for methamidophos were derived using BMD modelling . The results therefore seem to indicate that using RPFs that are derived from BMD modelling yields a higher estimated exposure level compared with using RPFs derived from NOAEL. In a study performed by Caldas et al (2006), they compared the output using both methamidophos and acephate where the majority of the RPFs were derived from BMD modelling for both compounds. They calculated the cumulative exposure to $34 \%$ and $70 \%$ of the ARfD for methamidophos and acephate respectively for the total population. The ARfD for methamidophos used in their study was $10 \mu \mathrm{g} / \mathrm{kg}$ bw/day, whereas we used $3 \mu \mathrm{g} / \mathrm{kg}$ bw/day as derived by EFSA. If an ARfD of $3 \mu \mathrm{g} / \mathrm{kg}$ bw/day had been used in their study, the ARfD would have been exceeded by more than $100 \%$.

In the study performed by Boon et al. (2008), they estimated the exposure for the organophosphates and carbamates separately with the argument that the mechanism of action is not quite the same for the organophosphorus and carbamate pesticides because of the difference in binding and binding time to the enzyme. In their study, levels below the LOR were assigned zero and the majority of the RPFs were derived from BMD modelling. They showed that if acephate is used as IC for the organophosphorus compounds, there might be a risk for the child population since the ARfD was exceeded by $14 \%$.

Another thing that makes a comparison with results obtained in other studies difficult is how the levels below the LOR are handled in the calculations. The LOR used to be rather higher for methamidophos for example, so using $1 / 2$ LOR in the calculation may result in a higher overestimation of the real exposure.

Despite the uncertainties in the calculation, the results in our study showed that the cumulative acute exposure is below $100 \%$ of the ARfD for both index compounds chlorpyrifos and methamidophos at the $99.9 \%$ percentile, which show that there is no cumulative acute risk from AChE compounds for consumers in Denmark.

\section{Commodities and pesticides that contributed most to the intake}

Apples contributed most to the cumulative intake when the two different index compounds chlorpyrifos (35\%) and methamidophos (45.5\%) were used. Carrots, table grapes, pears, white bread and lettuce were among the nine commodities that contributed most to the total intake in both cases. Wine contributed with $27.1 \%$ to the total intake when methamidophos was used as index compound, but only $2.2 \%$ when 
chlorpyrifos was used as index compound. Carbaryl was the only pesticide found in wine and the big difference in the size of contribution to the total intake can be explained by the difference in the relative toxicity of carbaryl compared with chlorpyrifos and methamidophos. As seen in Table I, carbaryl has a relative potency factor which is 0.07 of that for chlorpyrifos and a toxicity of 0.3 compared to methamidophos. This means that the relative toxicity for carbaryl compared to methamidophos is much higher than the relative toxicity for carbaryl compared to chlorpyrifos.

That apple contributed most to the intake was caused by the many detects from nine different pesticides (azinphos-methyl, carbaryl, chlorpyrifos, dimethoat, omethoate, malathion, parathion-methyl, phosmet and pirimicarb) and because of a high consumption. When we used methamidophos as IC, RPFs for only six of these compounds could be found. That means that the contribution from apples would be even higher if RPFs for all nine compounds could have been used in the calculation. However in future it is most likely that the exposure from organophosphates and carbamates will be less than calculated in this study, because many of the organosphos phosphates and carbamates are not included in Annex 1 to Directive 91/414 EEC and the authorizations will be or have been withdrawn for a number of these substances. For example, four of the pesticides found in apples (azinphos-methyl, carbaryl, omethoate, malathion) are not included in Annex 1 to Directive 91/414 EEC.

\section{Processing factors}

In the present study, many detects of organophosphates and carbamates were found in commodities which are peeled before consumption. Since the analyses are performed on the raw commodities, it would have a great impact on the calculated exposure if processing factors were used in the intake calculation. Without processing factors, the cumulative exposures were estimated to be $1.2 \%$ and $2.9 \%$ of the ARfD when chlorpyrifos was used as IC for the general population and children, respectively. This means that the inclusion of processing factors reduces the calculated exposure by $33 \%$ and $48 \%$, respectively ( $40.6 \%$ on average), which shows that this is a very important issue to address if we want the most realistic picture of the exposure estimate. 


\section{Effect of using $1 / 2$ LOR}

Due to the many non detects, the intake was increased by about $20 \%$ when levels below the LOR were set to $1 / 2$ LOR as opposed to zero. As explained by Raaij et al. (2005), it is probably closer to reality to assume that all non-detects are true zeros than to set all non-detects at $1 / 2$ LOR. However, if we use $1 / 2$ LOR in the calculation, we can get a worst case picture of the intake.

\section{Variability}

When the deterministic point estimate approach described by FAO/WHO (2001) is used in acute intake calculations, variability factors are applied in the NESTI calculations. Variability factors take into account that the residue concentration found in the composite sample can derive from only one of the units in the composite sample. In this study, no variability factors were used in the calculation of the cumulative exposure. In a cumulative exposure assessment where several commodities are assessed at the same time, it also seems unlikely that one would eat the crop in the composite sample with the highest residue level every time. Besides, there are as yet no guidelines on how to take variability into account in probabilistic exposure calculations (Boon et al., 2000). In the study performed by Boon et al. (2008), they developed an approach which simulates the variability factor by defining it as a model parameter. In the deterministic approach, the exposure level becomes higher when variability factors are used in the calculation, but this is not always the case when incorporating variability as done by Boon et al (2008). Since there is no agreed approach on how to incorporate variability in probabilistic modelling, this is an issue for further development and discussion in the future.

\section{Relative Potency Factor}

When RPFs were used, the two index compounds chlorpyrifos and methamidophos in the cumulative acute exposure calculations showed very different results in the level of exposure. If RPFs for all compounds for methamidophos could have been found, the differences would have been even higher. The RPFs for chlorpyrifos were derived from NOAEL while the majority of the RPFs for methamidophos were derived from BMD modelling. The results seem to indicate that the exposure is higher when the RPFs are derived from BMD modelling than when the RPFs are derived from NOAEL. So the toxicological data from which the RPFs are derived constitute another very important issue to address, and the difference between the RPFs derived from BMD modelling and NOAEL should be investigated. A thing that needs to be established is whether using BMD or NOAEL-derived RPFs gives the most realistic level of exposure.

\section{Conclusion}

We assessed the acute cumulative intake of organophosphorus and carbamate pesticides for consumers in Denmark using the probabilistic approach.

The assessment was performed using two different index compounds. We evaluated the risk to be much lower when chlorpyrifos was used as the index compound than when methamidophos was used. The different results show how important the choice of index compound is. It also seems that the exposure is higher when BMD-derived RPFs are used than when RPFs derived from NOAEL are used in the cumulative exposure 
calculation s. It should therefore be investigated which data are the most reliable for deriving the RPF values for various index compounds.

Many other uncertainties, such as food consumption data, residue data, the method used to perform the intake calculation, the use of processing factors and variability factors in the calculation, and the treatment of levels below the LOR, will have an effect on the calculation.

So guidelines on how to incorporate variability factors, for example, and how to address values below LOR in the calculations should be developed.

Despite the limitations and the uncertainties in the calculation of the dietary cumulative intake of the organophosphates and carbamates in the present study, the results show that the cumulative intake is below $100 \%$ of the ARfD for both chlorpyrifos and methamidophos at the percentile 99.9 for consumers in Denmark.

\section{References}

Andersen NL, Christensen T, Groth MG, Fagt S, Biltoft-Jensen A, Hartkopp H, Hinsh H-J, Matthiessen J, Moeller A, Saxholt E et al. 2005. The Danes dietary habits 20002002. Main results. [in Danish, summary in English]. Søborg (Denmark): Danish Institute for Food and Veterinary Research.

De Boer WJ, Van Voet H. 2007. MCRA, Release 6.A web-based program for Monte Carlo Risk Assessment. Biometris and RIKILT-Institute of Food Safety, Wageningen UR, Wageningen and National Institute for Public Health and the Environment (RIVM), Bilthoven.

Boon, P. and van Klaveren, J., 2003. Cumulative Exposure to Acetylcholinesterase Inhibiting Compounds in the Dutch Population and Young Children (2003.003). RIKILT - Institute of Food Safety. Wageningen UR, Wageningen. Available at www.rikilt.wur.nl

Boon PE, Tjoe Nij EIM, Donkersgoed G, Klaveren JD. 2004. (2004.005). RIKILT Institute of Food Safety. Wageningen UR, Wageningen. Available at www.rikilt.wur.nl

Probabilistic intake calculations performed for the Codex Committee on Pesticide Residues.

Caldas ED, Boon PE., Tressou J., 2006., Probabilistic assessment of the cumulative acute exposure to organophosphorus and carbamate insecticides in the Brazilian diet. Toxicology, 222:132-142.

European Food Safety Authority (EFSA) 2007. Opinion of the Scientific Panel on Plant protection products and their Residues on acute dietary intake assessment of pesticide residues in fruit and vegetables. The EFSA Journal 538: 1-88.

European Food Safety Authority (EFSA) 2008. Opinion of the Scientific Panel on Plant and their residues (PPR Panel) on a request from EFSA to evaluate the suitability of exciting methodologies and, if appropriate, the identification of new approaches to 
assess the cumulative and synergistic risks from pesticides to human health with a view to set MRLs for those pesticides in the frame of Regulation (EC) 396/2005. The EFSA Journal (2008) 704: 1-85.

EU Commission. Reg. (EC) No 396/2005

http://ec.europa.eu/food/plant/protection/pesticides/regulation_ec_396_2005_

Jensen AF, Petersen A, Granby K. 2003. Cumulative risk assessment of the intake of organophosphorus and carbamate pesticides in the Danish diet. Food Additives and Contaminants 20: 776-785.

FAO/WHO. 1997. Food Consumption and Exposure Assessment of Chemicals. WHO/FSF/FOS/97.5 (Geneva: WHO).

FAO/WHO, 2001, Pesticide Residues in Food - 2000. Report of the Joint Meeting of the FAO Panel of Experts on Pesticide Residue infood and the Environment and the WHO Core Assessment Froup on Pesticide Residues. Plant Production and Protection Paper 163 (Rome: FAO).

Manly, B.F.J, 1998. Randomization, bootstrap and Monte Carlo methods in biology. London: Chapman \& Hall.

Vose, D. 2000. Risk Analysis: a Quantitative Guide. 2. ed.,Wiley Chichester, England

Wilkinson C F, Christoph G R, Julien E, Kelley J M, Kronenberg J, McCarthy J, and Reiss R, 2000: Assessing the risks of exposures to multiple chemicals with a common mechanism of toxicity: How to cumulate? Regulatory Toxicology and Pharmacology, $31,30-43$.

Poulsen, M, Poulsen, M. E. et al. 2004, Pesticide Food Monitoring Program 19982003. Report concerning Directives 90/642/EEC, 86/362/EEC and Commision Recommendation 96/882/EC (Copenhagen; Danish Veterinary and Food Administration).

Raaij, M.T.M, Ossendorp, B.O., Slob, W., Pieters, M.N., 2005, Cumulative exposure to cholinesterase inhibiting compounds: a review of the current issues and implications for policy (320508001/2005). National Institute of Public Health and the Environment (RIVM), Bilthoven. Available at www.rivm.nl.

US EPA (2000b). Choosing a percentile of acute dietary exposure as a threshold of regulatory concern. Report No.6046.US Environmental Protection Agency. Washington DC. March 16. Available at http://www.epa.gov/pesticides/trac/science/trac2b054.pdf.

US EPA (2001). Organophoshate Pesticides: Preliminary OP cumulative Risk Assessment US. Environmental Protection Agency. Washington. DC. 20460. 2001. Avalilable at: http://www.epa.gov/pesticides/cumulative/pra-op/index.htm. 
EU 2008. Status of active substances under EU review (doc. 3010). European Commission. Available at

http://ec.europa.eu/food/plant/protection/evaluation/stat_active_subs_3010_en.xls 
Figure 1

Number of

positive samples
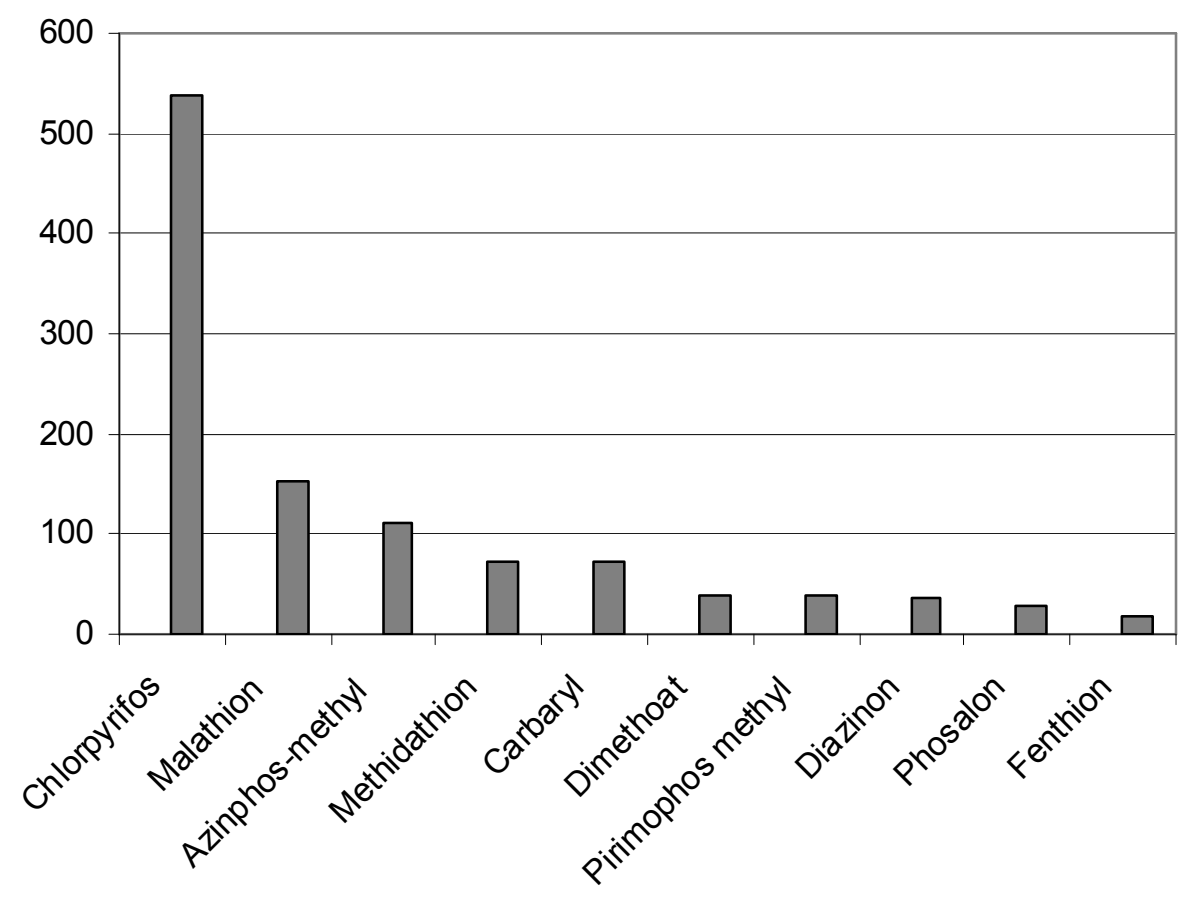
Figure 2

Deleted: 4

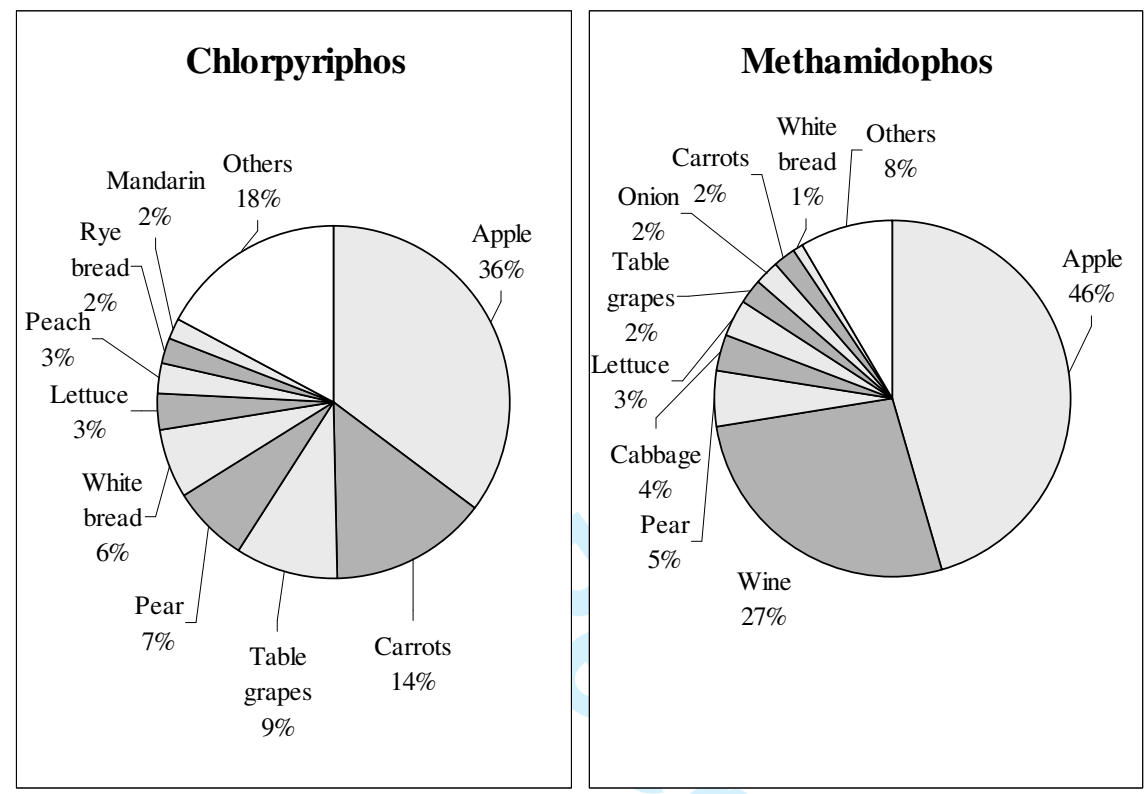




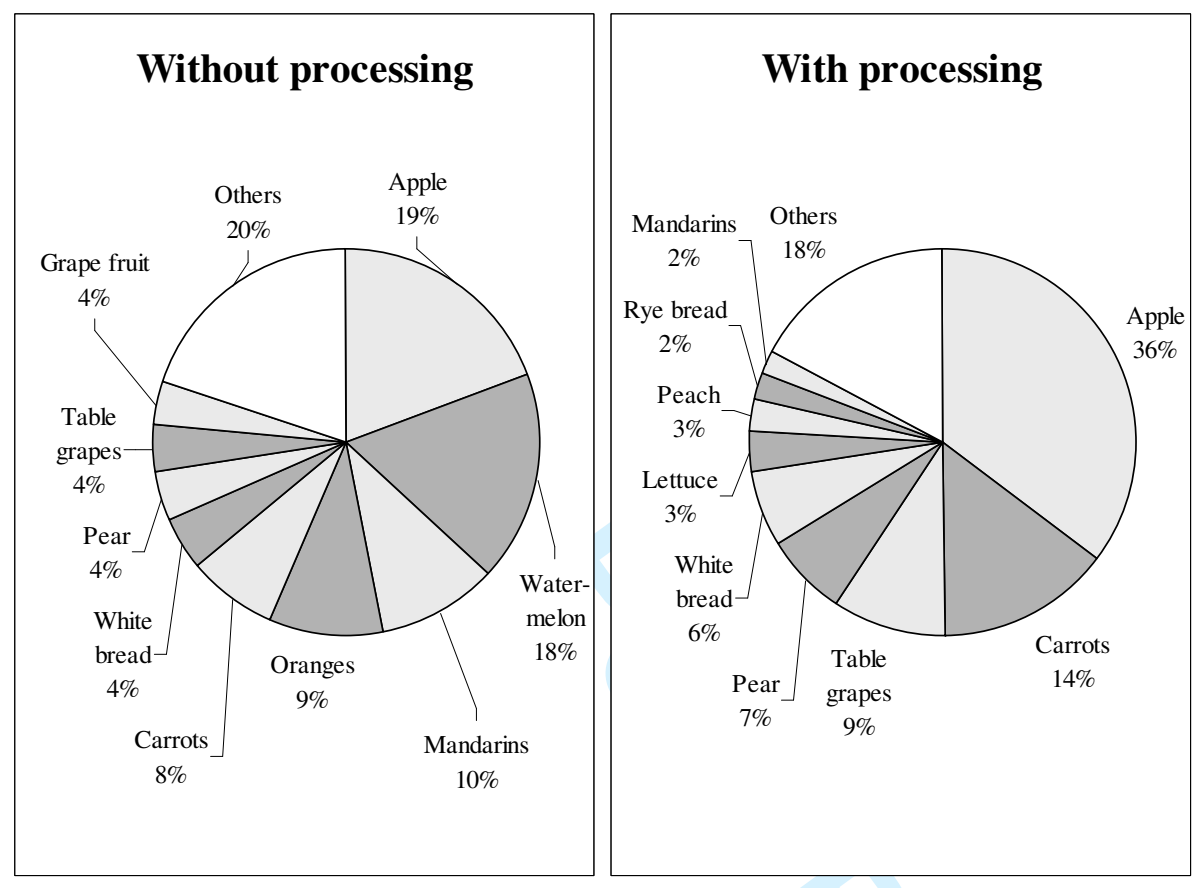




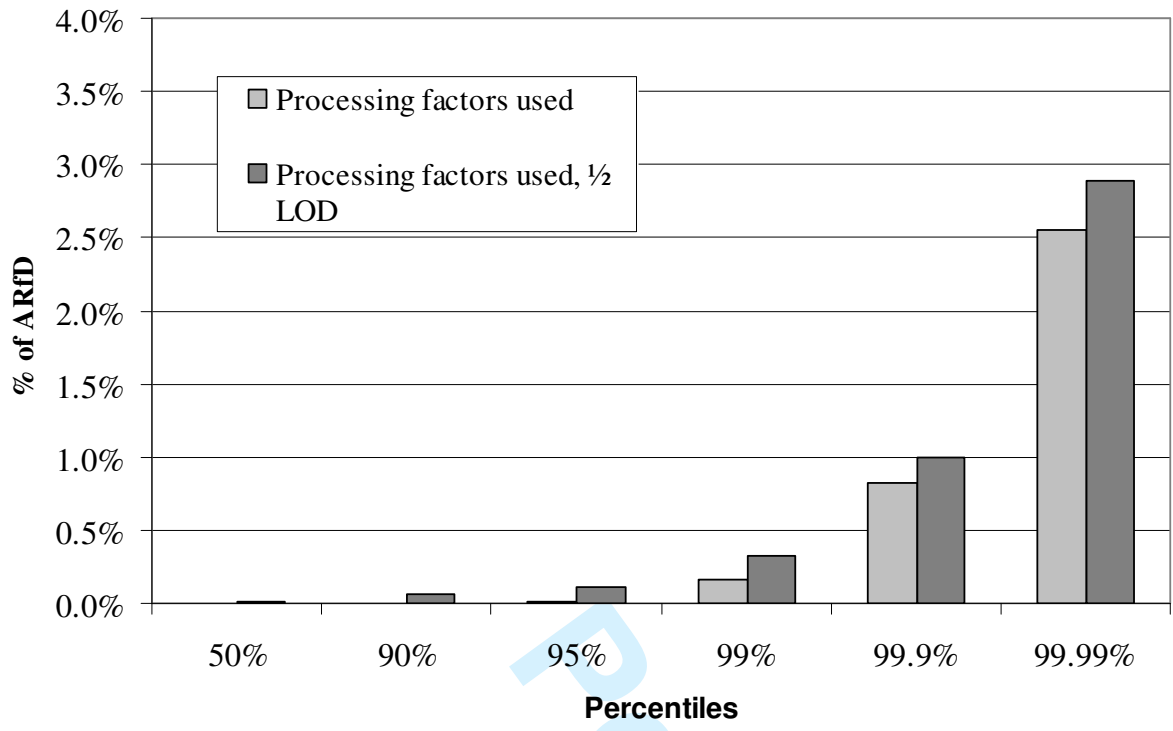


| Table I. Relative potency factors used in the cumulative assessment.

Table II. Summary of food consumption data from Danish national dietary survey 2000-2002.

Table III. Summary of residue data of actylcholinesterase inhibiting compounds on samples analyzed in the Danish monitoring programme during 2004-2007.

Table IV. The cumulative acute exposure using the two index compounds chlorpyriphos and methamidopos as index compounds. Data are shown for both children (4-6 years) and the general | population (4-74 years) at different percentiles, Levels $<\mathrm{LOR}=0$, processing factors applied.

Figure 1. Ten most frequently found organophosphate and carbamate pesticides in the 2004-2007 Danish monitoring programme.

Figure 2. Contribution (\% per product to the total distribution) for top nine commodities to the acute

Deleted: the most important exposure of organophosphates and carbamates for the general population (4-75 years) using chlorpyriphos as index compound. Calculations are shown with and without processing factors

| included in the calculations. Levels $<\mathrm{LOR}=0$

Figure 3. Acute cumulative intake using chlorpyriphos as index compound. Comparison between calculations performed between processing factors applied and with processing factors applied and levels below the LOQ entering into the calculation with $1 / 2 \mathrm{LOQ}$.

Figure 4. Contribution (\% per product to the total distribution) for the top nine commodities to the Deleted: the most important acute exposure of organophosphates and carbamates for the general population (4-75 years) using both chlorpyriphos and methamidophos as index compound. Levels $<\mathrm{LOR}=0$, processing factors applied. 
Table I

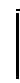

TEF, acute

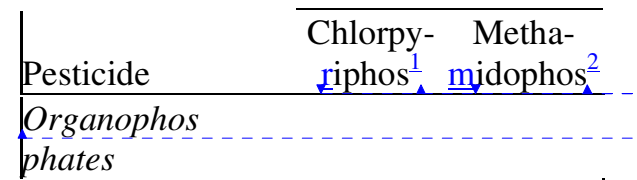

Acephate

Azinphos-methyl

Chlorfenvinphos

Chlorpyrifos

Diazinon

Dichlorvos

Dimethoate

Ethion

Fenitrothion

Fenthion

Malathion

$2 . .0 .08^{-}$

Methamidophos

Methidathion

Mevinphos

Omethoate

Parathion-methyl

Phosalone

Phosmet

2

$0.09^{\mathrm{b}}$

2.

$10.05^{\mathrm{b}}$

5

$0.03^{\mathrm{b}}$

$0.5,0.32^{\mathrm{b}}$

$2 \quad 1.1^{\mathrm{a}}$

0.02

1.43

0.02

$3.3,1.0^{-\mathrm{b}}$

5. $0.32^{\mathrm{b}}$

4

$\overrightarrow{4}$

9.1 $0.12^{\mathrm{b}}$

Pirimiphos-methyl $\quad \underline{0.5} 0.04^{\mathrm{b}}$

Profenofos $\quad 2 \quad 0.004^{\mathrm{b}}$

Tolclos-methyl

$\underline{0.02}$

Triazophos

0.83

$5.58^{\mathrm{a}}$

Carbamates

Carbaryl

$\underline{0.07}$

Carbofuran

$\overrightarrow{0.45}-1.5^{\mathrm{a}}$

Pirimicarb

$\underline{0.06}$

${ }^{1}$ RPFs were derived from acute NOAEL with inhibition of acetylcholinesterase in red blood cells and brain as critical effects. From Boon and Van Klaveren $(200 \overline{3})$

${ }^{2}$ RPFs were either derived form acute NOAEL with inhibition of acetylcholinesterase in red blood cells and brain as critical effects, marked with ${ }^{\mathrm{a}}$ or from benchmark dose at $10 \%$ acetylcholinestase inhibition $\left(\mathrm{BMD}_{10}\right)$, marked with ${ }^{\mathrm{b}}$. From Caldas et al (2006)

${ }^{a}$ RPF derived from NOAEL

${ }^{\mathrm{b}} \mathrm{RPF}$ derived from $\mathrm{BMD}_{10}$

\begin{tabular}{|l|}
\hline Formatted Table \\
\hline Deleted: $\mathrm{R}$ \\
\hline Deleted: $\mathrm{M}$ \\
\hline Formatted: Superscript \\
\hline Formatted: Superscript \\
\hline Formatted: Font: Italic \\
\hline Deleted: 2 \\
\hline Deleted: 0.2 \\
\hline Deleted: 9 \\
\hline Deleted: 20 \\
\hline Deleted: 1 \\
\hline Deleted: 50 \\
\hline Deleted: 20 \\
\hline Deleted: 25 \\
\hline Deleted: 0.6 \\
\hline Deleted: 0.2 \\
\hline Deleted: 0.71 \\
\hline Deleted: 2 \\
\hline Formatted: \\
\hline Deleted: 66.7 \\
\hline Foret: $11 \mathrm{pt}$ \\
\hline Deleted: 0.2 \\
\hline Deleted: 40 \\
\hline Deleted: 0.12 \\
\hline Deleted: 0.02 \\
\hline Deleted: 1.2 \\
\hline Deleted: 8.0 \\
\hline Deleted: 0.5 \\
\hline Deleted: 1.0 \\
\hline Deleted: 5 \\
\hline Deleted: 6 \\
\hline
\end{tabular}


Table II

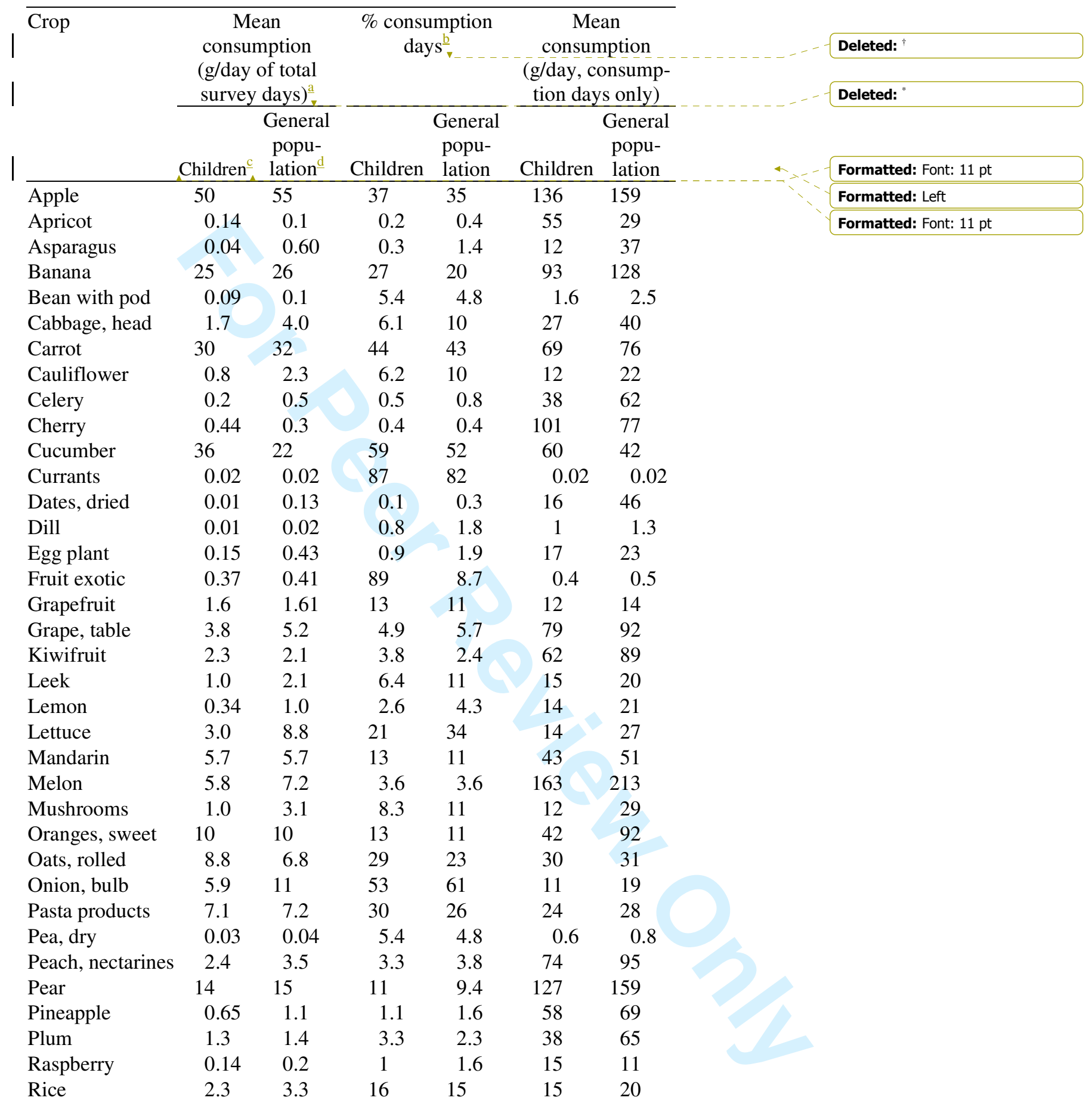




\begin{tabular}{lcccccc} 
Rye bread & 57 & 61 & 83 & 76 & 68 & 80 \\
Strawberry & 2.3 & 2.9 & 3.2 & 4.9 & 71 & 58 \\
Sweet pepper & 4.9 & 7.9 & 36 & 47 & 13 & 16 \\
Watermelon & 1.7 & 2.0 & 3.6 & 3.4 & 46 & 60 \\
Wheat bran & 0.15 & 0.24 & 1.5 & 2.5 & 9.4 & 9.8 \\
White bread & 75 & 92 & 83 & 85 & 90 & 108 \\
Wine & 0.0 & 63 & 0.0 & 19 & 0.0 & 345 \\
\hline
\end{tabular}

${ }^{\mathrm{a}}$ Included zero and non-zero consumption days.

$\%$ of non-zero consumption days for consumers.

${ }^{c}$ Children age $4-6$ years

${ }^{\mathrm{d} \text { General population age } 4-74 \text { years, }}$

Deleted:

Deleted:

Deleted: $\mathbb{I}$ 
Table $\prod_{t \in}$

\begin{tabular}{llll}
\hline Commodity & $\begin{array}{l}\text { Samples } \\
\text { analyzed }\end{array}$ & $\begin{array}{l}\text { Samples } \\
\text { detected }^{*}\end{array}$ & $\begin{array}{c}\text { Mean positive } \\
\text { concentration }^{\dagger} \\
(\mathrm{mg} / \mathrm{kg})\end{array}$
\end{tabular}

\begin{tabular}{|c|c|c|c|c|c|}
\hline Apple & 3867 & 163 & $(4.2 \%)$ & 0.0667 & Chlorpyriphos \\
\hline Apricot & 136 & 6 & $(4.4 \%)$ & 0.0259 & Azinphos-methyl \\
\hline Asparagus & 26 & 2 & $(7.7 \%)$ & 0.0895 & Chlorpyriphos \\
\hline Banana & 440 & 20 & $(4.5 \%)$ & 0.0227 & Chlorpyriphos \\
\hline Basil & 9 & 1 & $(11 \%)$ & 0.9090 & Parathion-methyl \\
\hline Bean with pod & 508 & 17 & $(3.3 \%)$ & 0.1426 & Dimethoat \\
\hline Cabbage, head & 38 & 1 & $(2.6 \%)$ & 0.0850 & Dimethoat \\
\hline Carrot & 819 & 18 & $(2.2 \%)$ & 0.0895 & Chlorphenvinphos \\
\hline Cauliflower & 73 & 2 & $(2.7 \%)$ & 0.0027 & Dimethoat \\
\hline Celery & 64 & 4 & $(6.3 \%)$ & 0.0143 & Diazinon \\
\hline Cherry & 24 & 3 & $(13 \%)$ & 0.0260 & Dimethoat \\
\hline Cucumber & 375 & 2 & $(0.5 \%)$ & 0.0460 & Methamidophos \\
\hline Currants & 138 & 4 & $(2.9 \%)$ & 0.0116 & Phosmet \\
\hline Dates, dried & 23 & 1 & $(4.3 \%)$ & 0.2273 & Parathion-methyl \\
\hline Egg plant & 160 & 3 & $(1.9 \%)$ & 0.0253 & Carbaryl \\
\hline Fruit exotic & 346 & 48 & $(14 \%)$ & 0.0513 & Carbaryl \\
\hline Grapefruit & 1476 & 102 & $(6.9 \%)$ & 0.2431 & Chlorpyriphos \\
\hline Grape, table & 744 & 33 & $(4.4 \%)$ & 0.1369 & Carbaryl \\
\hline Kiwifruit & 713 & 15 & $(2.1 \%)$ & 0.0390 & Diazinon \\
\hline Leek & 66 & 2 & $(3.0 \%)$ & 0.0185 & Acephate \\
\hline Lemon & 988 & 85 & $(8.6 \%)$ & 0.2992 & Chlorpyriphos \\
\hline Lettuce & 1196 & 33 & $(2.8 \%)$ & 0.0758 & Dimethoat \\
\hline Mandarin & 2616 & 259 & $(9.9 \%)$ & 0.1485 & Chlorpyriphos \\
\hline Melon & 745 & 9 & $(1.2 \%)$ & 0.1060 & Chlorpyriphos \\
\hline Mushrooms & 47 & 1 & $(2.1 \%)$ & 0.0018 & Carbaryl \\
\hline Oranges, sweet & 3319 & 159 & $(4.8 \%)$ & 0.1564 & Chlorpyriphos \\
\hline Oats, rolled & 63 & 2 & $(3.2 \%)$ & 0.0178 & $\begin{array}{l}\text { Pirmimipnos- } \\
\text { methyl }\end{array}$ \\
\hline Onion, bulb & 115 & 4 & $(3.5 \%)$ & 0.0019 & Carbaryl \\
\hline Pasta products & 25 & 1 & $(4.0 \%)$ & 0.0145 & $\begin{array}{l}\text { Pirimiphos- } \\
\text { methyl }\end{array}$ \\
\hline Pea, dry & 16 & 1 & $(6.3 \%)$ & 0.0220 & Dimethoat \\
\hline Peach, nectarines & 900 & 68 & $(7.6 \%)$ & 0.0440 & Azinphos-methyl \\
\hline Pear & 1831 & 56 & $(3.1 \%)$ & 0.0738 & Azinphos-methyl \\
\hline Pineapple & 144 & 10 & $(6.9 \%)$ & 0.0100 & Carbaryl \\
\hline Plum & 1479 & 23 & $(1.6 \%)$ & 0.0474 & Chlorpyriphos \\
\hline Raspberry & 56 & 1 & $(1.8 \%)$ & 0.0049 & Carbaryl \\
\hline
\end{tabular}




\begin{tabular}{|c|c|c|c|c|c|}
\hline Rice & 137 & 10 & $(7.3 \%)$ & 0.0081 & Malathion \\
\hline Rye bread & 334 & 8 & $(2.4 \%)$ & 0.0099 & $\begin{array}{l}\text { Pirimiphos- } \\
\text { methyl }\end{array}$ \\
\hline Strawberry & 859 & 9 & $(1.0 \%)$ & 0.0488 & Chlorpyriphos \\
\hline Sweet pepper & 417 & 3 & $(0.7 \%)$ & 0.0540 & Methamidophos \\
\hline Watermelon & 4 & 3 & $(75 \%)$ & 0.0822 & Methamidophos \\
\hline White bread & 868 & 20 & $(2.3 \%)$ & 0.0163 & methyl \\
\hline Wine & 81 & 7 & $(8.6 \%)$ & 0.0021 & Carbaryl \\
\hline
\end{tabular}


Table IV

\begin{tabular}{cccccc}
\hline & \multicolumn{2}{c}{ IC Chlorpyriphos } & & \multicolumn{2}{c}{ IC Methamidophos } \\
\cline { 2 - 3 } \cline { 5 - 6 } Percentile & \multicolumn{2}{c}{ 95 \% confidence } & \multicolumn{2}{c}{$\begin{array}{c}\text { 95 \% confidence } \\
\text { \% of ARfD }\end{array}$} & $\begin{array}{c}\text { interval } \\
\text { interval }\end{array}$ \\
\hline Children 4-6 years & & & & & \\
95 & 0.04 & $(0.03-0.05)$ & & 0.13 & $(0.10-0.2)$ \\
95 & 0.39 & $(0.28-0.5)$ & & 1.5 & $(1.0-2.2)$ \\
99.9 & 1.8 & $(1.2-2.4)$ & & 31 & $(20-60)$ \\
99.99 & 5.8 & $(2.3-8.8)$ & & 115 & $(75-196)$ \\
General population & $4-75$ years & & & & \\
95 & 0.02 & $(0.01-0.03)$ & & 0.13 & $(0.06-0.23)$ \\
99 & 0.16 & $(0.12-0.2)$ & & 1.1 & $(0.65-2.3)$ \\
99.9 & 0.83 & $(0.57-1.1)$ & & 14 & $(6.0-23)$ \\
99.99 & 2.6 & $(0.97-5.8)$ & 46 & $(18-86)$ \\
\hline
\end{tabular}

